\title{
REVIEW
}

\section{Future of primary healthcare education: current problems and potential solutions}

\section{J Lord}

Postgrad Med J 2003;79:553-560

This review examines the origins of primary care and the pressures currently faced in terms of patient expectation, regulation, accountability, and work force shortages. It recognises the appropriateness of adding to the burden in primary care further by the shift both of more services and more medical education from secondary care. Some conclusions are drawn concerning potential solutions including skill mix changes, centralisation of services, a change in attitudes to professional mistakes, increased protected development time, evidence based education, and academic, leadership, and feedback skills for general practitioners. Six recommendations are offered as a prescription for organisational and educational change.
Correspondence to: Professor J Lord, School of Human and Health Sciences, Harold Wilson Building, University of Huddersfield

Huddersfield, West Yorkshire HDI 3DH, UK; j.lord@hud.ac.uk

\section{WHERE HAS PRIMARY CARE COME FROM, AND WHERE IS IT GOING}

During the last century in the UK, primary care has transformed from a cottage industry, as captured by Doctor Finlay's Casebook, ${ }^{1}$ to become the principal site of interaction for one of our largest nationalised industries. Where will it go in the future and how can its educational needs be anticipated?

One model that places primary care in the wider picture of all health and disease interventions and services is the clinical iceberg (fig 1), where the ice represents those people who are symptomatic, ill, or who make contact with health care.

Like any iceberg most of its bulk is below the water line. The submerged section represents the part of the general population who do not present to a clinician. Some of these people have symptoms and some self medicate. In this model, those people interacting with health care are above the water line. The largest proportion of these are seen in primary care and smaller numbers in secondary and tertiary care.

The proportion of people with significant illness (dots in fig 2) might be expected to increase the "higher up the iceberg" they are sited, though there will be some people with symptomless pathology at the bottom.

This triangular diagram represents the position from 80 years ago, the time portrayed by Dr Finlay, until the introduction of the National Health Service (NHS). Since then the ice has effectively been widened not because of population increase, but because of increased demand from the addition of new therapies and investigations, world travel, and an ageing population (fig 3). Patients of retirement age consult their general practitioner (GP) 50\% more frequently than those under $65 .^{3}$

The proportion of the visible iceberg allocated to primary care is also increased by the shift of the management of chronic illness away from hospitals, often described as secondary to primary care shift (fig 4).

Continuing with this metaphor, the water line has been lowered by the introduction of screening and by a new "consumerism": awareness is raised by media health scares and there are increased expectations of immediate solutions from health care providers. The extremes of human physique and ability have become accepted as diagnoses-like short stature and

Abbreviations: GP, general practitioner; GPsWSIs, GPs with special interests; NHS, National Health Service; $\mathrm{PRHO}$, pre-registration house officer

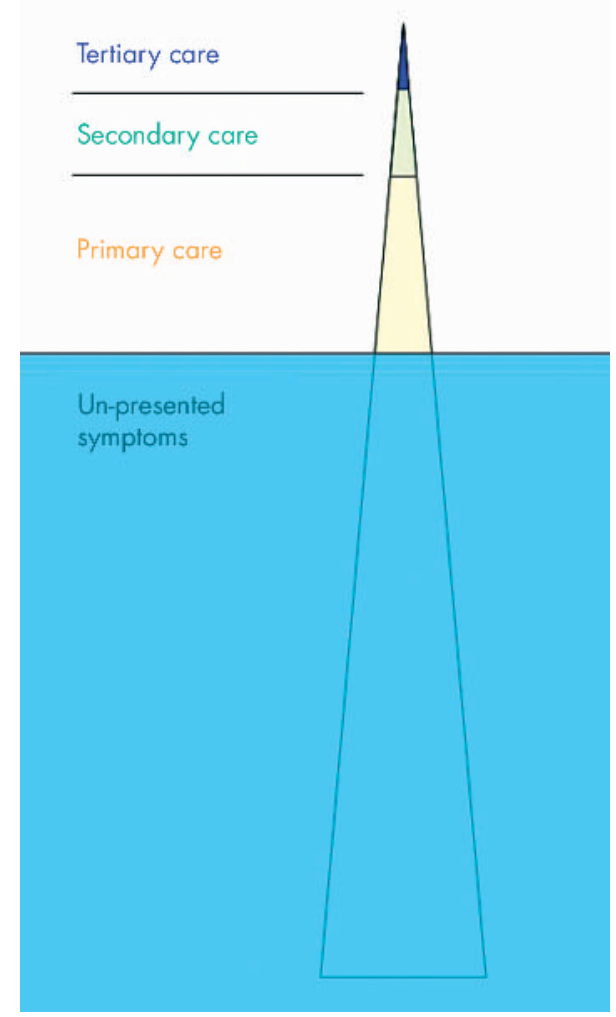

Figure 1 The "clinical iceberg". 


\section{Rules for rules}

- Rules should be small in number.

- Created by the periphery of society that will use them, not the centre.

- Be about safe minimum baselines, not possible ideals the limits of acceptable behaviour, but not directing the details of behaviour.

(Willis, The Paradox of Progress ${ }^{16}$ )

dyspraxia. For good or ill, more of life has become medicalised (fig 5).

The increased activity in primary care has in part been achieved by an increase in the numbers of GPs ${ }^{4}$ and in part by skill mix changes. Practice nurses have usually been appointed to undertake screening and much of the chronic disease management that was transferred from secondary care.

GPs with special interests (GPsWSIs), pronounced "gypsies", form a new layer in the ice-

berg between primary and secondary care (fig 6).

It is envisaged that they will help to provide specialist services in liaison with a local consultant specialist. They may accept referrals from other GPs and/or act as gatekeeperprioritisers, and could be involved in the review of many patients currently followed up in secondary care.

Unfortunately that is not the end of the story. The shape of the iceberg is not a slender triangle.

Just beneath the waterline lurks its main bulk (fig 7).

Only a small minority of people with symptoms present to healthcare. Most people have symptoms and many self medicate. ${ }^{5}$ It is fortunate that the population remains as yet so self reliant, for it would need only a very small change in the water line to swamp the NHS (fig 8).

There is a hazard in government pursuing a policy of rapid access for minor ailments, in advance of successful schemes to address the workforce recruitment and retention.

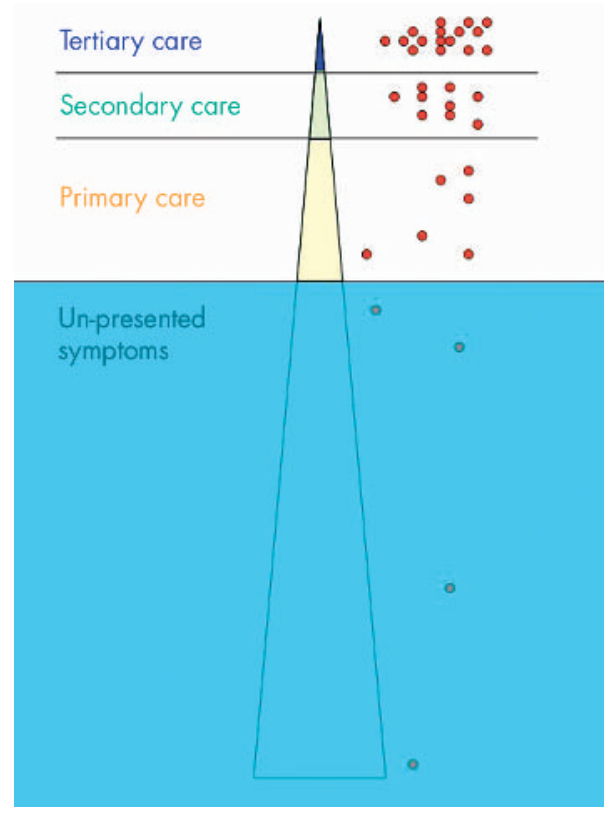

Figure 2 Life threatening illness.

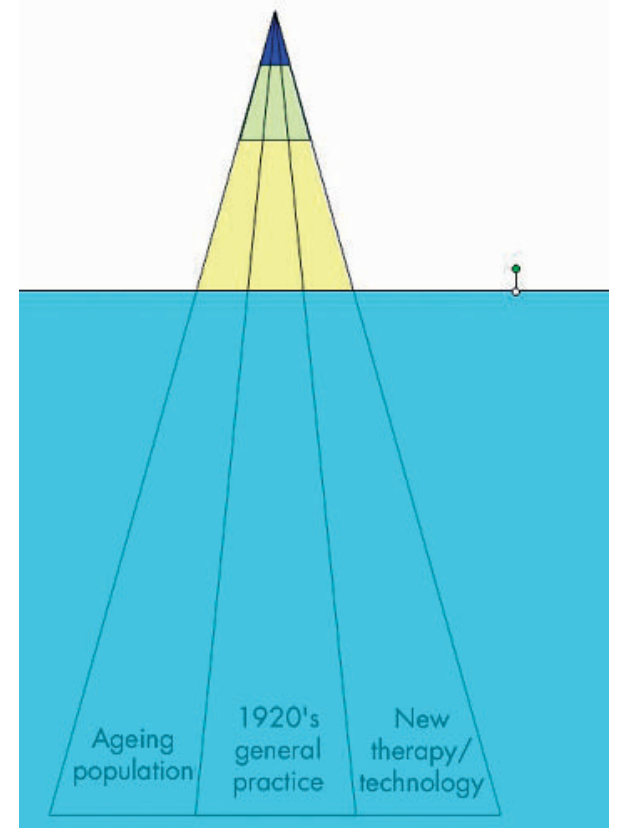

Figure 3 More treatments to offer.

\section{EXPECTATIONS}

Patients value primary care very highly ${ }^{3}$ but also have high expectations for more and better services. Half of all women would prefer to see a female GP, and 37\% would prefer to see a GP of their own ethnic group. ${ }^{6}$ Longer consultation times have generally been considered to be important in the delivery of high quality clinical care, ${ }^{78}$ and to be associated with a range of better patient outcomes. ${ }^{9}$ Though from the patient's perspective, having a clinician who listens and who involves the patient is more important than a long consultation. ${ }^{10}$ Demands for rapid access ${ }^{11}{ }^{12}$ and longer opening hours are not easily compatible with longer consultations, continuity, ${ }^{13}$ the standards published by the Department of Health "Improving Working Lives", ${ }^{14}{ }^{15}$ or with the expectations of new healthcare workers for a life outside work.

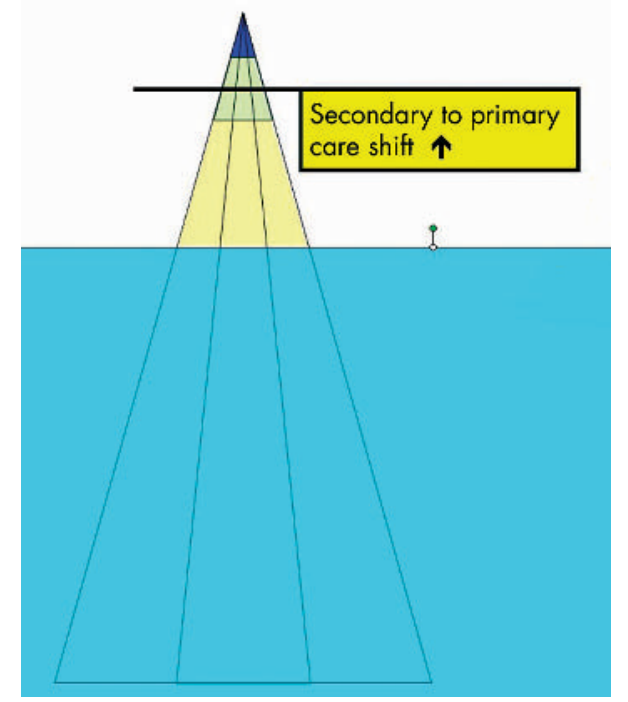

Figure 4 Secondary to primary care shift. 


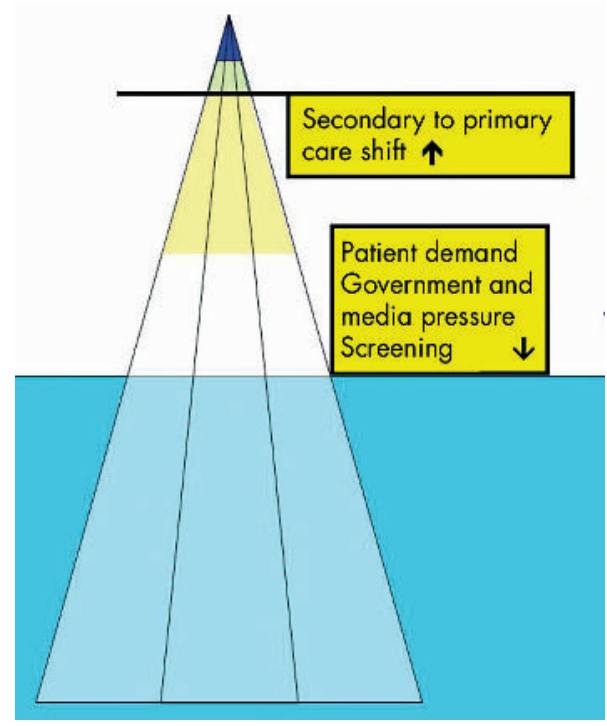

Figure 5 More demand.

\section{REGULATION AND ACCOUNTABILITY}

Increased demand for accountability may be inevitable in the wake of the series of recent scandals that included Bristol heart surgery, retained body parts at Alder Hey Hospital, and the Dr Shipman murders. Revalidation and appraisal are positive aspects to increasing accountability. Appraisal in particular offers an excellent opportunity to prepare detailed personal development plans with peer support.

However, there is also a risk that individual patient freedom will be curtailed by over-enthusiastic application of population based statistics. In contradiction with James Willis's "rules for rules" (box 1$)^{16}$ and its own propaganda concerning a primary care led NHS, ${ }^{11}{ }^{17-19}$ central government increasingly regulates and micromanages healthcare in the

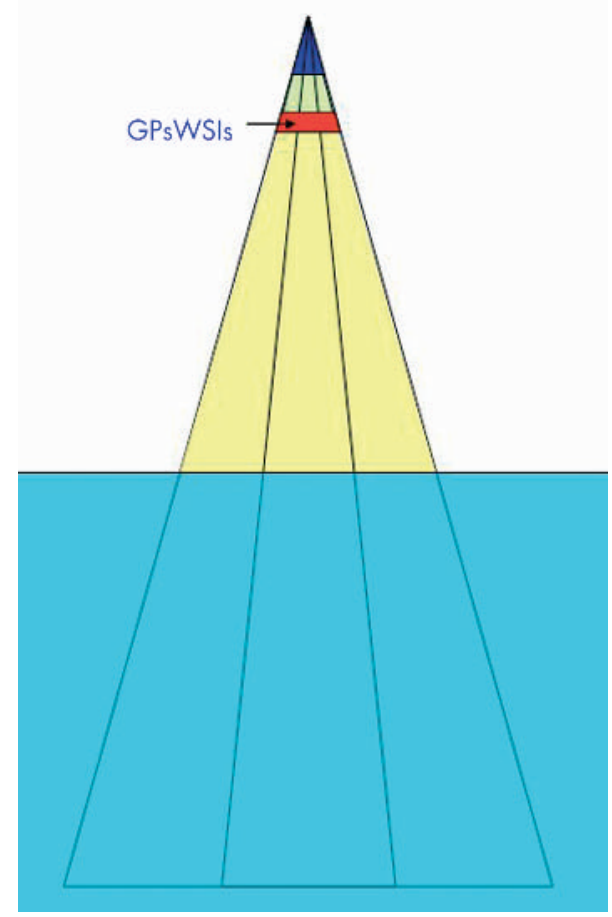

Figure 6 GPs with special interests (GPsWSIs).

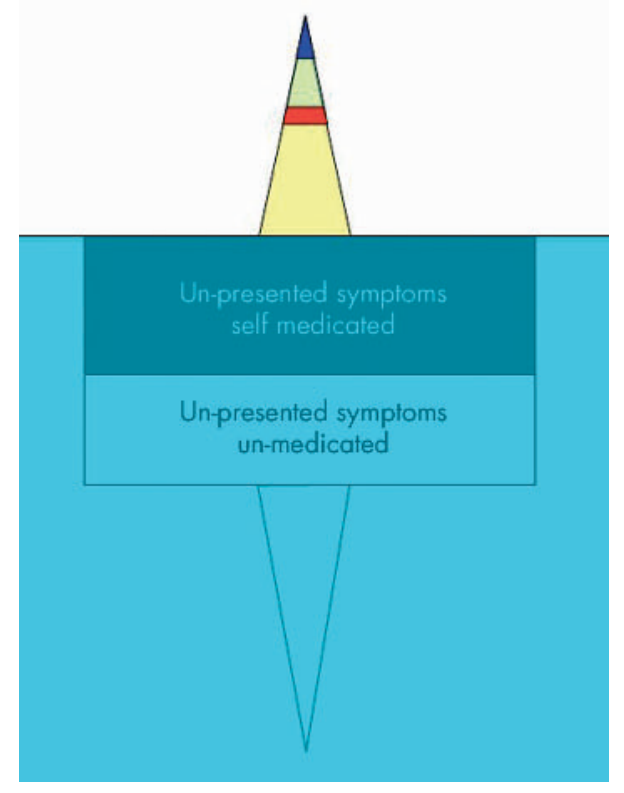

Figure 7 Un-presented symptoms.

name of accountability, dictating precisely how a clinician must respond in an ever increasing range of situations. ${ }^{20}$

Protocols may work for the average patient, but not for every patient. If clinicians develop the rules, more patients will fit. However, the current style of micromanagement still limits patient centred care and reduces the opportunity for patients' self determination and choice. For example the new GP contract ${ }^{12}$ proposes that GPs be remunerated on the basis of the proportion of patients with ischaemic heart disease who are prescribed $\beta$-blockers, angiotensin converting enzyme (ACE) inhibitors, and anticoagulants. A truly patient centred approach would require discussion with the patient and shared decision making rather than medication by government diktat.

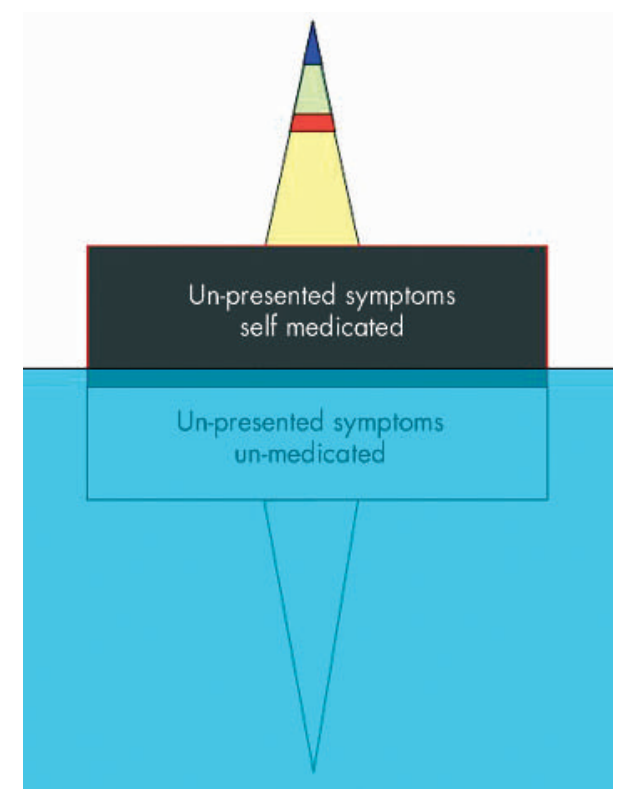

Figure 8 Danger in asking patients to present earlier. 


\section{HUMAN RESOURCE CRISIS}

Compared with the European Union, the UK has half the doctors per capita. ${ }^{21}$ For many years there has been a trend for increasing numbers of GPs and consequently smaller list sizes, and the potential for longer appointments. ${ }^{3}$ However the implementation of the NHS plan will require approximately 2000 more GPs. ${ }^{22}$ In addition, the UK is already short of approximately 1000 GPs. This is represented by a persistent vacancy rate of $3.4 \% .{ }^{23}$ GPs often feel isolated and are unhappy, stressed and demoralised, ${ }^{24}$ though not just in the $\mathrm{UK}^{25}$

About a quarter of GPs wish to retire in the near future ${ }^{26}$ mainly because of reduced job satisfaction. ${ }^{27}$ In many deprived areas half GPs over age 50 intend imminent retirement. ${ }^{3}$ GPs currently work an average 58 hours per week, ${ }^{3}$ so if they were employees at least half would fail to comply with the European Union working hours directive. Many would prefer to work in a part time or salaried capacity, and if given the opportunity would further reduce the numbers of available whole time equivalent GPs. Others prefer to work alone. ${ }^{28}$ While there is concern about the isolation of solo GPs, quality standards for single handers appear to be similar to those for other GPs. ${ }^{29}$ Single handers tend to be older and closer to retirement. ${ }^{28}$ Wanless predicted that, even with the existing increased entry to medical schools, by 2020 the UK will be short of 25000 doctors, and will be particularly short of GPs. ${ }^{21}$

This shortage of clinicians also extends to nurses. Compared with the European Union, the UK also has only half the nurses per capita, ${ }^{21}$ and there is difficulty in recruitment and retention. ${ }^{30} 31$ Most NHS nurses are employed in secondary care and of those who work in primary care, one third are approaching retirement age. ${ }^{3}$

\section{SKILL MIX}

The Department of Health plans to make the NHS more multidisciplinary $^{12}$ and holistic. ${ }^{32-34}$ Practice nurses could perform telephone triage effectively, though the cost is at present borne by the GP, ${ }^{35}$ and produces no overall reduction in costs. ${ }^{36}$

Nurse practitioners could subsume more of the functions of $\mathrm{GPs}^{3}{ }^{22}$ in practices, or in walk-in centres, ${ }^{37}$ but in the last decade little progress has been made towards developing this new professional group. ${ }^{33}$ Nurse practitioner consultations tend to be about one third longer than GP consultations, but to be more acceptable to patients and otherwise similar in outcome ${ }^{3}{ }^{38-40}$ and cost. ${ }^{41}$

There are 10 times as many nurses per doctor in secondary care compared with primary care. ${ }^{3}$ Increasing use of nurses working at a higher level, and as the first point of contact in healthcare is mentioned in NHS policy. ${ }^{21}$ However, the policy still needs to be converted into reality. As yet there is insufficient development opportunity for nurses. In primary care they often cannot attract backfill payments, or find locum cover. More courses need to be available for the training of primary care nurse practitioners. Even if sufficient educational opportunities are provided, nurse practitioners are likely to be recruited from the already insufficient numbers of practice nurses, community nurses, and health visitors. It may be preferable to introduce physician assistants, who often come from occupations other than healthcare. There is increasing use of physician assistants in the USA ${ }^{42}$ but the role has as yet not been tried much in the UK. ${ }^{43}$ However, it is my contention that the use of physician assistants should be piloted and investigated as a matter of urgency. This could provide a partial solution to the dearth of GPs in northern urban areas. The training of physician assistants could provide additional clinical personnel without depleting the ranks of existing nurses. They could be trained relatively quickly. A physician assistant in training could be apprenticed to a GP. The GP would spend some time as a mentor/tutor, but in return gain more in the form of support and delegation of minor tasks. Such a format would increase the appeal of the work both for the physician assistants and for GPs, and aid the recruitment and retention of both. One third of all illness presenting in primary care consists of a rash or respiratory infection. ${ }^{4}$ Physician assistants could be trained just to manage these problems at first.

\section{CENTRALISATION}

Eighty percent of primary care premises are too small 3 ; $66 \%$ of these premises need to be upgraded or replaced by $2006 .{ }^{21}$ The new GP contract includes provision for investment in buildings. ${ }^{12}$ This presents an ideal opportunity to change building locations and size to match future requirements. There is a considerable pressure for amalgamation and centralisation. As above, patients want a wider range of services, more choices of clinician, longer consultations, and rapid access at a wider choice of times. Some of this could be achieved by amalgamating more services and practices under one roof. There is the potential for central premises (or a limited number of locality sites) in each primary care organisation area to house all required services: primary care organisation administration, 24 hour walk in centre staffed by a GP and by nurse practitioners, 24 hour pharmacy, 24 hour urgent home visit service, physiotherapy, GPsWSIs, podiatry, benefits advice, phlebotomy, services for the homeless and for substance abusers, community mental health team, counselling, psychologists, dentists, opticians, and complimentary therapies. Under such a system there could be other shared infrastructure such as computing, management, and transport. Currently patients moving house a short distance within a town may have to re-register with a new GP, but with centralisation, patients could choose to stay with any doctor even when they move within the primary care organisation area.

Much GP time is spent in home visits to the elderly. ${ }^{44} 45$ However, nurse practitioners specialising in the care of the elderly, and supplementary nurse prescribers ${ }^{46}$ could undertake reviews of medicines and many of these home visits. Currently GPs have to fulfill the impossible demand of being in two places at once-that is consulting in the surgery, but yet able to attend emergencies at home visits. Large practices can ensure that only one GP is allocated to this emergency visiting role, but centralisation would make this facility available to all. Innovations in transport are encouraged. ${ }^{12}$ The provision of a people carrier style vehicle and driver can substantially reduce the need for home visits. ${ }^{47}$ Such innovations permit the retention of the scarce GP resource centrally with little need for them to leave the building, and could significantly increase their turnover of work.

\section{DIVERT PATIENTS AND FUNDS TO ECONOMICAL SERVICES}

In terms of patient contact, secondary care is 36 times more expensive than primary care: nine out of 10 NHS patients are seen in primary care, ${ }^{22}$ yet primary care accounts for only one fifth of NHS spending. ${ }^{3}$ Secondary care continues to increase its expenditure six times as fast as primary care ${ }^{3}$ There is a potential efficiency to be achieved by following the example of Eire in diverting funds to primary care. ${ }^{48}$ A $5 \%$ shift in total patient contacts would halve the outpatient workload for secondary care. It is inconceivable that the current cost ratios would apply-that is, move $5 \%$ of NHS contacts for $1 \%$ of the NHS budget. The cost of shifting $5 \%$ of NHS contacts to primary care would therefore be greater, but even if it consumes $10 \%$ of the budget it could still be worth doing. It cannot be long before government will calculate the most 
efficient division of labour, so we must expect further secondary to primary care shift. When it comes, it is important to ensure that adequate resource moves with these patients and that workload shift is not just lost within current promised uplift of $11 \%$ over each of three years. ${ }^{12}$

\section{PRIMARY CARE BASED GENERAL MEDICAL EDUCATION}

Historically undergraduate medical education has been based on a secondary care curriculum. This has the merit that the majority of medical students will exit into hospital based roles. However, there is a need for education to reflect the core position of primary care in the new NHS. The new curricula offer very exciting possibilities for medical students: increasingly undergraduate medical teaching involves primary care. ${ }^{49}$ In fact it is viewed as essential by the General Medical Council. ${ }^{50}$ This primary care experience provides a good opportunity to learn consultation skills and experience common problems not seen in hospital, to understand the management of undifferentiated problems and the value of continuity of care.

Since 1997 four months of the pre-registration house officer (PRHO) year may be undertaken in primary care. Those PRHOs who work in primary care report a high level of planned educational input that is less interrupted by service pressures. This is cited as the reason for their greater enthusiasm and satisfaction than their secondary care based counterparts. ${ }^{51}$

General practice vocational training schemes have particular aims focusing on good communication skills, patient centred medicine, the ability to tolerate uncertainty, effective use of time, working in multidisciplinary teams, preventative medicine, valuing diversity, and organisational skills. They encourage reflective practice and put the needs of the learner to the fore. They usually contain half a day of protected time (half day release) per week to attend a curriculum based course, a minimum of three hours protected tutorial time per week, opportunity to discuss cases during and after each surgery/clinic, and sessions to develop communication skills by observing video recordings of their own consultations. Some schemes also offer a one week residential summer school. ${ }^{52}$ Innovatory and combined community/primary/secondary care training posts are beginning to appear, for example working part time in a hospice and part time in general practice.

It is expected that all doctors will spend some postregistration foundation training working as a GP. ${ }^{53}$ GP registrars have to learn more flexible approaches including a tolerance both for the expression of feelings and for uncertainty. They also have to unlearn strategies heavily reliant on investigation, or on addressing the doctor's agenda at the expense of the patient's. ${ }^{54}$ I look forward to a more humane, patient centred approach to training ${ }^{34}$ based even more in primary care.

Continuing medical education for GPs had been excessively reliant on accredited teaching events, often in the form of ineffective didactic lectures. ${ }^{55}$ A major new direction was established by the Chief Medical Officer's report on continuing professional development for GPs. ${ }^{56}$ This raised the profile of individual learning styles and needs, team and work based learning, and firmly established accredited learning in the form of practice and personal development plans. Personal development plans will be almost universal, once appraisal has been fully implemented.

There is increasing use of an adult learning model ${ }^{57}$ in which problems are addressed by the team, so as to develop an interprofessional understanding. Much important interprofessional learning remains informal. ${ }^{58} \mathrm{~A}$ conversation on the stairs between community nurse and GP could provide important insight for either party.

\section{CULTURAL CHANGE - HONESTY AND SHARED DECISIONS}

Undergraduate and hospital experience encourages a professional culture of independent self reliance and the ability to defend judgments by logical argument or adversarial debate. While these are valuable attributes in themselves, all too often the consequent medical culture avoids expressions of doubt, misgiving, or inadequacy. ${ }^{59}$ This benefits neither the patient nor the doctor. Smith described how patients and doctors may collude in a bogus contract deceiving each other. ${ }^{60}$ In this, the doctor is all capable and free from doubt. Perhaps we all have a duty to support a change of culture. Eliminating blame may begin with the adoption of Smith's suggestion of a new contract embracing joint decision making with patients and honest realism about our limited power and knowledge. A further step is usually described as "systems thinking", ${ }^{61}$ where errors are ascribed to faulty working systems rather than to human inadequacy. I prefer to think of it as "the wedding present principle": how many of us received sets of glasses as house warming or wedding presents, use them, and still have complete sets? Glass is easily broken, but if we are $100 \%$ vigilant at all times surely we could keep the glass intact. However, even when life or limb is at risk, human beings cannot maintain that level of concentration. Performance does not seem to be enhanced by raising the stake, as is the case with a treasured gift, or the threat of blame and litigation. When we discover repeated clinical error, how should we respond: blame the clinician or change the system? In order to learn from error we need to accept human fallibility, and change the systems in work that permit errors to re-occur. "we cannot change the human condition, we can change the conditions under which humans work" ${ }^{\prime 62}$ The review, not just of errors, but of near misses, complaints, and surprise successes can be of great educational benefit to individuals and teams. This is usually described as significant event analysis. ${ }^{63-65}$ It is at its most instructive, when the whole team attends, and each person involved relates their part of the story. A blame free culture and the confidential support of colleagues ${ }^{66}$ are important precursors for such events to take place.

\section{TITHE}

Covey describes how we would berate a lumberjack who was attempting to fell a tree using blunt implements. ${ }^{67}$ The lumberjack would achieve his task much faster and with much less effort if he took a short break to sharpen his saw. But how regularly do we put time aside to sharpen our minds, and what proportion of working time should be devoted to such personal development?

Two percent (one week in one year) has long been the accepted standard funded by the Post Graduate Education Allowance. Personally, I think that this is grossly inadequate, and that it is time that another standard was set, that is more in keeping with the unprecedented rate of change created by developments in therapeutics, research, and legislation.

I would like to propose a tariff-a minimum quota for time spent in personal development. I suggest a tithe-10\%. That is, in a five day working week, half a day is spent examining, reflecting upon, and improving our mental tools. One session per week should be reserved for staff development. This is an absolute minimum, for there is so much to be done: continuing professional development, teaching and learning, audit, clinical governance, organisational and team development, and feedback that involves patients in a learning organisation. ${ }^{6168}$ 


\section{Key recommendations}

- More clinical work and more education could and should occur in primary care, but resources must genuinely follow diverted activity.

- The human resource crisis in primary care needs addressing now, partly by training nurse practitioners and physician assistants, and partly by centralisation of services.

- Systems thinking can promote a culture of trust and honesty, both with patients and with colleagues.

- Patients, not managers, should set the quality agenda. To achieve this patients need the opportunity to be involved.

- As an absolute minimum, $10 \%$ (a tithe) of professional time should be in self/team development.

- Simple evidence based adjustment to educational techniques could easily be adopted in primary care.

How do we create a $10 \%$ level of development time? Simplistically one could argue for a $10 \%$ inflation in the numbers of all staff; we could stop doing the least worthwhile $10 \%$ of what we do now, or redistribute work with the development of new roles. I suspect that the answer lies in a mixture of all three: some more resources, some new roles, streamline some activity.

A tithe is something that is due. It is the clinician's right to time for development, the patient's right to clinicians who are capable and up to date, the manager's duty to provide and protect the time. In-work protected time for staff to learn together is already Department of Health policy, ${ }^{11}{ }^{12} 69{ }^{70}$ as is time out for practices to undertake critical reviews, ${ }^{3}$ but lack of protected time is often associated with failure to meet training needs. ${ }^{71}{ }^{72}$ Clinical governance alone is expected to take $10 \%$ of working time by $2010 .{ }^{21}$ A tithe is for now, by then it will not be enough. Longer periods of study and reflection may also be needed at some points. A sabbatical ${ }^{73} 74$ or other prolonged study ${ }^{75}$ may be helpful mid-career, and these are beginning to be recognised in policy. ${ }^{12} 76$

\section{EVIDENCE BASED EDUCATION}

Medical teachers would like to be able to demonstrate the same kind of evidence base for their educational technique as is becoming available for clinical practice. ${ }^{77}$ However it is not easy to obtain results that are generalisable ${ }^{78}$ particularly in terms of outcomes, ${ }^{79}$ and cost effectiveness. ${ }^{80}$ There is a tension between student centred adult learning, and the blinded application of a randomised yet consistent teaching intervention. ${ }^{81}$ The interval between intervention and an outcome that matters can be so long that confounding influences are to be expected..$^{82}$

There is, however, a body of evidence neatly summarised by Thomson O'Brien et al, who suggest that diverse and interactive learning is to be preferred in medicine. ${ }^{83}$ This supports the assertions of expert writers on teaching like Brookfield who propounded that "The principle of diversity should be engraved on every teacher's heart" ${ }^{\prime \prime 4}$ and the promotion of the use of a range of methods to accommodate different learning styles and different needs.

The advance organiser concept in which a skeletal framework is provided outlining the nature of what is to be learnt is of value in school education. ${ }^{85}$ Development of this with primary care teams appears to demonstrate that discussion of what the team needs to achieve in learning helps the team to apply their learning by making subsequent change to

\section{Key references}

- Zwanenberg T, Harrison J, eds. GP tomorrow. 2nd Ed. Abingdon: Raddliffe Medical Press, 2002.

- Audit Commission. A focus on general practice in England. London: Audit Commission, 2002.

- Donaldson L. Unfinished business: proposals for reform of the senior house officer grade. London: Department of Health, 2002.

- Wanless D. Securing our future health: taking a longterm view: final report. London: HM Treasury, 2002.

- Senge P. The fifth discipline, the art and practice of the learning organisation: Doubleday, 1990.

- Calman KC. A review of continuing professional development in general practice. London: Department of Health, 1998.

practice. ${ }^{86}$ Simple evidence based interventions like this could easily be incorporated into conventional teaching.

There is the potential for the GP role to be isolated. Peer support methods of education, like interprofessional action learning sets,$^{74}$ may help to reduce this. Other examples of peer support include clinical supervision, mentorship, and appraisal. There seems to be a particular place for structured peer review at practice visits. ${ }^{24} 7387$

\section{ACADEMIC AND LEADERSHIP DEVELOPMENTS}

There is a need to introduce management and leadership skills into medical education ${ }^{88}$ both for survival in terms of avoiding burn out, ${ }^{89}$ and to develop integrated interprofessional teams. ${ }^{90}$ There are particular points of vulnerability as a practitioner that are beginning to be supported. Flexible training schemes make some allowance for family life. Higher professional education and career start schemes ${ }^{91}{ }^{92}$ help GPs to settle into practice rather than be "thrown in at the deep end". Ongoing support beyond the first year or two of practice is important in establishing GPs who are committed to life long learning. There may be opportunities to support more than one group of young professionals at the same events, for example new nurse practitioners meeting with young GP practitioners.

There are too few GP academics: only 1.6\% of doctorates of medicine between 1973 and 1988 were awarded to GPs. ${ }^{93}$ Other academic activities such as writing of papers, peer review of articles, and teaching are the exception rather than the norm. The debate continues as to whether new principals should, like other specialists, be members of their Royal College. With most of the NHS contacts, and designated patient lists, primary care could form a "natural laboratory" ${ }^{\prime 4}$ However, primary care remains exceptionally short of its own evidence base. Often it is reliant on data, of questionable generalisability, obtained from secondary care. ${ }^{95}$ Perhaps the most important new GPsWSIs posts to establish should be academic and in leadership.

\section{APPRAISAL AND FEEDBACK}

Central government's commitment to development planning, development portfolio maintenance for all, ${ }^{96}$ and to appraisal for GPs is to be commended. Appraisal provides an avenue for educational support for all GPs, and can give them the opportunity to recognise new learning situations and methods such as e-learning and the NHS University. ${ }^{97}$ There has been considerable geographical variation in spending on education. ${ }^{71}$ Appraisal may go some way to addressing this inequality, by providing the same opportu- 
nities for challenge and support to all GPs, and by encouraging them all to recognise educational opportunities. Appraisal is also an opportunity to introduce feedback; not just from the appraiser, but from patients. Some patient questionnaires and feedback merely make the clinician feel valued or the converse. Greco suggests a format for requesting feedback from patients so as to create opportunities for the clinician to improve. ${ }^{98}$ While there is still uncertainty about the extent to which patients should be involved in health care management, ${ }^{99}$ empowered patients may be the agent best able to redirect managers from a performance indicator fixation to the issues that really matter, but that may be harder to measure. ${ }^{100}$

\section{COMPETING INTERESTS/ACKNOWLEDGEMENT}

$\mathrm{JL}$ is a module leader for a leadership MSc and a nurse practitioner MSc. He also works part time as a general practitioner.

This review is partly based on an inaugural professorial lecture at the University of Huddersfield.

\section{REFERENCES}

1 Cronin AJ. Adventures in two worlds. London: Gollancz, 1952.

2 Fraser RC. Clinical method: a general practice approach. London: Butterworths, 1987.

3 Audit Commission. A focus on general practice in England. London: Audit Commission, 2002.

4 Jones R, Menzies S. General practice: essential facts. Abingdon: Raddliffe Medical Press, 1999.

5 Wadsworth MEJ, Butterfield W, Blaney R. Perception of illness and use of services in an urban community. Health and sickness: the choice of treatment. London: Tavistock, 1971.

6 NHS Executive. National surveys of NHS patients general practice 1998 London: NHSE, 1999

7 Williams M, Neal RD. Time for a change? The process of lengthening booking intervals in general practice. Br J Gen Pract 1998:48:1783-6.

8 Campbell SM, Hann M, Hacker J, et al. Identifying predictors of high quality care in English general practice: observational study. BMJ 2001;323:784-90.

9 Freeman GK, Horder JP, Howie JGR, et al. Evolving general practice consultation in Britain: issues of length and context. BMJ 2002;324:880-2.

10 Jenkins $\mathrm{L}$, Britten $\mathrm{N}$, Barber $\mathrm{N}$, et al. Consultations do not have to be longer. BMJ 2002;325:388.

11 Department of Health. The NHS plan. London: DoH, 2000

12 NHS Confederation. New GMS contract 2003: investing in general practice. London: British Medical Association, 2003.

13 Bower P, Roland M, Campbell J, et al. Setting standards based on patients' views on access and continuity: secondary analysis of data from the general practice assessment survey. BMJ 2003;326:258-63.

14 Department of Health. Improving working lives standard: NHS employers committed to improving the working lives of people who work in the NHS. London: DoH, 2000

15 Department of Health. Improving working lives for doctors. London: DoH, 2002.

16 Willis J. The paradox of progress. Abingdon: Raddliffe Medical Press, 1995

17 Department of Health. The new NHS: modern, dependable. London: DoH, 1997.

18 Department of Health. A first class service. Consultation document on quality in the NHS, HSC 1998/113. NHSE, Leeds. Leeds: NHS Executive, 1998.

19 Department of Health. Shifting the balance of power within the NHS. London: DoH, 2001

20 Walshe K. The rise of regulation in the NHS. BMJ 2002;324:967-70.

21 Wanless D. Securing our future health: taking a long-term view: final report. London: HM Treasury, 2002

22 Department of Health. Primary care, general practice and the NHS Plan. London: DoH, 2001

23 Mayor S. England short of 970 GPs. BMJ 2003:326:243.

24 Frost C. Primary care, the emotive workplace: understanding and addressing the feelings generated within the GPs role. London: WONCA EUROPE, 2002.

25 Puddester D. The Canadian Medical Association's policy on physician health and well-being. West J Med 2001;174:5-7.

26 Kmietowicz Z. Quarter of GPs want to quit, BMA survey shows. BMJ 2001;323:887

27 Sibbald B, Bojke C, Gravelle H. National survey of job satisfaction and retirement intentions among general practitioners in England. BMJ 2003;326:22-25.

28 Green J. The views of singlehanded general practitioners: a qualitative study. BMJ 1993;307:607-10.

29 Hippisley-Cox J, Pringle M, Coupland C, et al. Do single handed practices offer poorer care? Cross sectional survey of processes and outcomes. BMJ 2001;323:320-3

30 Buchan J, Edwards N. Nursing numbers in Britain: the argument for workforce planning. BMJ 2000;320:1067-70.

31 Finlayson B, Dixon J, Meadows S, et al. Mind the gap: the extent of the NHS nursing shortage. BMJ 2002;325:538-41.
32 Department of Health. A health service of all the talents: developing the NHS workforce. London: DoH, 2000.

33 Department of Health. Making a difference. London: DoH, 1999.

34 Department of Health. Modernising medical careers - the response of the four UK health ministers to the consultation on unfinished business. London: $\mathrm{DoH}$ 2003.

35 Lattimer V, Sassi F, George S, et al. Cost analysis of nurse telephone consultation in out of hours primary care: evidence from a randomised controlled trial. BMJ 2000;320:1053-7.

36 Richards DA, Meakins J, Tawfik J, et al. Nurse telephone triage for same day appointments in general practice: multiple interrupted time series trial of effect on workload and costs. BMJ 2002;325:1214-20.

37 Jones $M$. Walk-in primary medical care centres: lessons from Canada. BMJ 2000;321:928-31.

38 Horrocks S, Anderson E, Salisbury C. Systematic review of whether nurse practitioners working in primary care can provide equivalent care to doctors. BMJ 2002;324:819-23.

39 Kinnersley P, Anderson E, Parry K, et al. Randomised controlled trial of nurse practitioner versus general practitioner care for patients requesting "same day" consultations in primary care. BMJ 2000;320:1043-8.

40 Shum C, Humphreys A, Wheeler D, et al. Nurse management of patients with minor illnesses in general practice: multicentre, randomised controlled trial. BMJ 2000:320: 1038-43.

41 Venning P, Durie A, Roland $M$, et al. Randomised controlled trial comparing cost effectiveness of general practitioners and nurse practitioners in primary care. BMJ 2000;320:1048-53.

42 Mittman DE, Cawley JF, Fenn WH. Physician assistants in the United States. BMJ 2002;325:485-7.

43 Hutchinson L, Marks T, Pittilo M. The physician assistant: would the US model meet the needs of the NHS? BMJ 2001;323:1244-7.

$44 \mathrm{McNiece} \mathbf{R}$, Majeed A. Socioeconomic differences in general practice consultation rates in patients aged 65 and over: prospective cohort study. BMJ 1999:319:26-8

45 Aylin P, Majeed FA, Cook DG. Home visiting by general practitioners in England and Wales. BMJ 1996;313:207-10.

46 Department of Health. Supplementary prescribing by nurses and pharmacists within the NHS in England. Available online at http://www.doh.gov.uk/ supplementaryprescribing/supp-prescribe-guidefinal.pdf (accessed 8 April 2003)

47 Lord J, Kitching $\mathrm{H}$. Home visiting and the implementation of a transport scheme (unpublished work 2003).

48 Payne D. Irish government to revamp primary care. BMJ 2001;323:1323.

49 Howe A, Hand C. The challenge of doing things differently: one new medical school's vision of primary care education. Education for Primary Care 2002;13:205-14.

50 General Medical Council. Tomorrow's doctors: recommendations on undergraduate medical education. Available online at http://www. gmc-uk.org/med_ed/tomdoc.htm (accessed 14 March 2003)

51 General Medical Council. Implementing The New Doctor. Available online at http://www.gmc-uk.org/med ed/itnd.htm (accessed 14 April 2003).

52 Summer school. Available online at http://www.yorkshiredeanery.com/ generalPractice/generalPractice.asp (accessed 14/4/2003).

53 Donaldson L. Unfinished business: proposals for reform of the senior house officer grade. London: Department of Health, 2002.

54 Metcalfe D. Medical schools - a poor preparation for general practice. In: Moreton $\mathrm{P}$, ed. The very stuff of general practice. Abingdon: Radcliffe Medical Press, 1999:155-69.

55 Bligh DA. What's the use of lectures? 2nd Ed. Exeter: Intellect Books, 2002.

56 Calman KC. A review of continuing professional development in general practice. London: Department of Health, 1998

57 Knowles M. The adult learner: a neglected species. 4th Ed. Houston, TX: Gulf Publishing, 1990.

58 Davies C. Getting health professionals to work together. BMJ 2000;320:1021-2.

59 Berger A. Surviving (and even enjoying) medicine. BMJ 2000;320:2.

60 Smith R. Why are doctors so unhappy? BMJ 2001;322:1073-4.

61 Senge $\mathbf{P}$. The fifth discipline, the art and practice of the learning organisation. New York: Doubleday, 1990.

62 Reason J. Human error: models and management. BMJ 2000;320:768-70.

63 Department of Health. An organisation with a memory: report of an expert group on learning from adverse events in the NHS. London: DoH, 2000.

64 Department of Health. Building a safer NHS for patients: implementing organisation with a memory London: $\mathrm{DoH}, 2001$.

65 Pringle M. Significant event auditing. In: Zwanenberg T, Harrison J, eds. Clinical governance in primary care. Abingdon: Raddliffe Medical Press, 2000:105-15.

66 Glencross I. Significant event audit in Huddersfield [report supporting MSc dissertation]. Huddersfield: University of Huddersfield, 2002.

67 Covey SR. The 7 habits of highly effective people, powerful lessons in personal change. London: Simon \& Schuster, 1989.

68 Davies HTO, Nutley SM. Developing learning organisations in the new NHS BMJ 2000:320:998-1001

69 Department of Health. "Working together-learning together: a framework for lifelong learning for the NHS. London: DoH, 2001

70 Department of Health. Learning for everyone: a development plan for NHSU. London: DoH, 2002.

71 Audit Commission. Hidden talents: education, training and development for healthcare staff in NHS. London: Audit Commission, 2001.

72 King N, Firth J, Frost C. Education needs assessment amongst primary care staff in Huddersfield. Primary Care Research Conference, 2001; University of Huddersfield, 2001. 
73 Grant J, Chambers E, GJ. The good CPD guide: a practical guide to managed CPD. Surrey: Reed Healthcare, 1999.

74 Morley V. Helping GPs reflect mid career. In: Harrison J, Zwanenberg T, ed. GP tomorrow 2nd Ed. Abingdon: Radcliffe Medical Press, 2002:139-54.

75 Bridge DT, Gilbert J. An international work exchange: better than a midlife crisis. BMJ 1998;317:1709-10.

76 Department of Health. Prolonged study leave. Available online at http:// www.doh.gov.uk/hrinthenhs/learning/section2b/ introductionhomepage.htm (accessed 4 April 2003)

77 Petersen S. Time for evidence based medical education. BMJ 1999;318:1223-4.

78 Hutchinson L. Evaluating and researching the effectiveness of educational interventions. BMJ 1999;318:1267-9.

79 Wilkes $M$, Bligh J. Evaluating educational interventions. BM 1999;318:1269-72.

80 Brown CA, Belfield CR, Field SJ. Cost effectiveness of continuing professional development in health care: a critical review of the evidence. BMJ 2002;324:652-5.

81 Prideaux D. Researching the outcomes of educational interventions: a matter of design. BMJ 2002;324:126-7.

82 Norman G. Research in medical education: three decades of progress. BMJ 2002;324:1560-2.

83 Thomson O'Brien M, Freemantle N, Oxman A, et al. Continuing education meetings and workshops: effects on professional practice and health care outcomes. The Cochrane Database of Systematic Reviews 2001(4).

84 Brookfield SD. The skillful teacher: on technique, trust, and responsiveness in the classroom. San Francisco: Jossey-Bass, 1990.

85 Ausubel DP, Novak JD, Hanesien H. Educational psychology: a cognitive view. 2nd Ed. New York: Holt, Rinehart \& Winston, 1978.

86 Lord J. Does the addition of a focussing technique improve learning for primary healthcare teams? [dissertation] Leeds: University of Leeds, 2002
87 Hasler J. Peer review through practice visits. In: Pendleton D, Hasler J, eds. Professional development in general practice. Oxford: Oxford University Press, 1997:71-80.

88 Pencheon D. Development of generic skills. BMJ 1998;317:2

$89 \mathrm{O}^{\prime}$ Neil E. Leading to well-being: the 5 key elements of healthy leadership. West J Med 2001;174:34-6.

90 Zwanenberg T. GP tomorrow. In: Zwanenberg T, Harrison J, eds. GP tomorrow. 1st Ed. Abingdon: Raddliffe Medical Press, 1998.

91 Bradford City PCT. Working and learning together-starting the teaching PCT journey. Available online at http://www.doh.gov.uk/pricare/teachingpcts/ bradfordannual2002.pdf (accessed 8 April 2003).

92 Harrison J, Redpath L. Career start in County Durham. In: Harrison J, Zwanenberg T, eds. GP tomorrow. 1st Ed. Abingdon: Radcliffe Medical Press, 1998:59-74.

93 Williams W. A survey of doctorates by thesis among general practitioners in the British Isles from 1973 to 1988. Br J Gen Pract 1990;40:491-4.

94 Bonati M. Primary care is natural place for clinical research and practice. BMJ 2000;321:1529.

95 Wilson S, Delaney BC, Roalfe A, et al. Randomised controlled trials in primary care. BMJ 2000;321:24-7.

96 Department of Health. NHS Plan implementation programme. London: DoH, 2000.

97 Department of Health. NHSU: learning for everyone. Available online at http://www.nhsuniversity.nhs.uk/ (accessed 8 April 2003).

98 Greco M, Cavanagh M, Bownlea A, et al. The Doctor's Interpersonal Skills Questionnaire (DISQ): a validated instrument for use in GP training. Education for General Practice 1999; 10:256-64.

99 Crawford MJ, Rutter D, Manley C, et al. Systematic review of involving patients in the planning and development of health care. BMJ 2002;325:1263-7.

100 Squires B, Learmonth I. Empowerment of patients-fact or fiction? BMJ 2003;326:710.

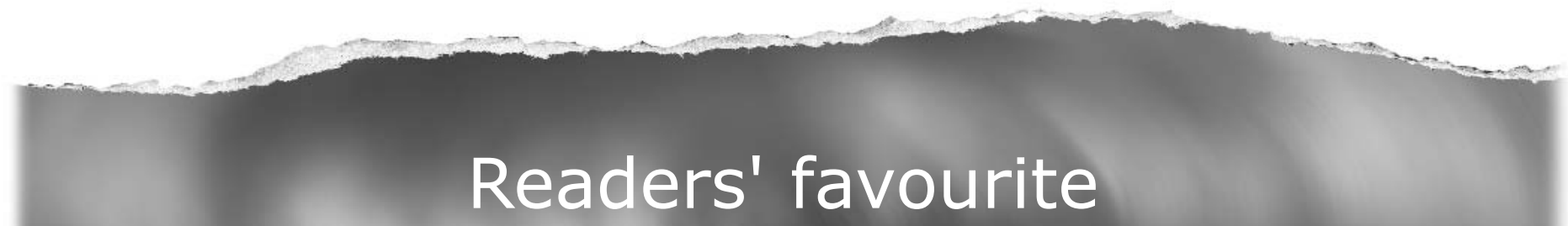

Top 10

Click on the "Top 10" button on the homepage to see which are the best read articles each month

\section{www.postgradmedj.com}

